\title{
The Full VAT/GST Liability Regime of Digital Platforms in the Collection of Taxes on Online Sales
}

\author{
Ilija Gruevski ${ }^{1}$, Stevan Gaber ${ }^{2}$
}

UDC 339.1:004.738.5]:336.226.322(100)

${ }^{1}$ Goce Delcev University, Faculty of Economics, Krste Misirkov St., 10-A, RepublicofMacedonia, e-mail: ilija.gruevski@ugd.edu.mk

${ }^{2}$ Goce Delcev University, Faculty of Economics, Krste Misirkov St., 10-A, RepublicofMacedonia, e-mail: stevan.gaber@ugd.edu.mk

It is unarguable that development of electronic markets and other digital platforms facilitated the transactions between buyers and sellers and continuously contributed to the rapid growth of online trade. This trend has never been more obvious during the pandemic crisis as the evidence suggests that more than two-thirds of all cross-border e-commerce sales of goods around the world are made through online markets. The growing significance of this segment is raising the question for a more efficient and effective collection of VAT/GST on online sales of goods, services and intangibles. Some jurisdictions have already implemented measures that obligate digital platforms to collect VAT/GST on online sales, and more imortantly, have reported positive outcomes in improving compliance and tax revenue gains. Encouraged by these results, the OECD initiated a developement of internationally accepted standards and measures for the efficient involvement of digital platforms in the VAT/GST collection on online sales. The aim of this article is to present a short elaboration of the OECD practical guidelines and principles on the design and implementation of the possible solutions for involvement of e-markets and other digital platforms as a viable VAT/GST collection means. Eventually, it can serve as an initial frame for domestic and other authorities for the possible implementation of such a similar measure, especially in near future, as every additionally collected revenues may become more important.

\section{Keywords}

Value Added Tax (VAT), Goods and Services Tax (GST), Full VAT/GST liability regime, digital platforms, digital economy, tax reform, tax policy.

\section{Introduction}

Digital economy has never been more influential on international trade than nowadays, when the COVID-19 pandemic has restricted physical and social contacts, closed the economies worldwide and fundamentally changed everything that humans have used to do before. Electronic marketplaces and digital platforms, which are some of the most essential constituents of digital economy, play a central role in the continuous strong growth of online trade by enabling sellers and buyers to interact and make transactions. Numbers indicate that almost two-thirds of all cross-border e-commerce sales (before the pandemic) were realized through online marketplaces. These radical shifts in business customs and the way international sales and trade are done, are opening new windows of opportunities for a more efficient and reliable collection of VAT/GST, especially on online sales of goods, services and 
intangibles to private consumers. A number of jurisdictions have already recognized the moment for the possibility to engage digital platforms as a person liable for collecting, assessing and remitting VAT/GST on online sales. Against all odds, the pioneering countries have reported encouraging initial results and have reported successful outcomes in terms of compliance improvement and increased tax revenue. This was inspiring for the OECD, to begin the development of internationally agreed set of measures for the inclusion of digital platforms in the VAT/GST collection on online sales, serving as a guidance frame in case of implementation for the intending jurisdictions.

The goal of this article is to present and describe the approach in tax policy, where digital platforms are obligated to asses, collect and remit VAT/GST on online sales, with the imposition of the full VAT/GST regime. This is part of the new reform in the field of VAT/GST, that has been undertaken recently by the OECD in the context of an accelerating digitalization and globalized economy. Several studies establish recommendation for the standards and mechanisms of this concept. The most relevant are: "Base Erosion and Profit Shifting", "The Role of Digital Platforms in the Collection of VAT/GST on Online Sales", "International VAT/GST Guidelines", "Addressing the Tax Challenges of the Digital Economy" "Mechanisms for the Effective Collection of VAT/GST" and others. These are extensively reviewed for the purpose of the article, and with application of adequate methods, we competently present the full VAT/GST regime of digital platforms, as a competitive mean for collection of revenues. As a messenger of the new trends in tax policy, we hope that our work will draw the attention at least of the tax authorities, as they will find it useful to consider this as a beginning frame in the attempts to reform and modernize internally.

\section{The Explosive Growth of Online sales}

It is more than obvious that the rapid digitalization of the economy and the pandemic have launched the explosive growth of online sales and have permanently changed the nature of retail sales of goods and services to private consumers (business-to-consumer or B2C sales). Under the usual (common) circumstances, a consumer would traditionally make a purchase of a certain good from a local store. Now, in the era of digital economy, his first choice would be an order from the website of the store or from an online domestic or international supplier, with other words, a digital platform where many suppliers advertise and offer their products for sale. The impact of the digital economy on the international trade and its implications, have brought new challenges for the policymakers, participating actively in the numerous reforms and projects from this important field under the provision of the OECD.

Just to illustrate the scale of online sales, it has been estimated that the global $\mathrm{B} 2 \mathrm{C}$ ecommerce sales of goods alone to be worth of 2 trillion USD annually (in the region of the dollar influence) with projections reaching USD 4.5 trillion by 2021 (considering the COVID-19 pandemic, this numbers could be much larger), from which 1 trillion USD is estimated to be cross-border e-commerce [1]. Other sources indicate similar figures. For example, according to eMarketer, global retail e-commerce sales reached USD 2.8 trillion in 2018, which is estimated to grow to USD 4.8 trillion by 2021 [2]. Numbers from the Asia-Pacific Economic Cooperation indicate that global B2C e-commerce sales reached USD 2.1 trillion in 2017 [3], while the same figure summed USD 3.8 trillion in 2016 according to the World Trade Organization [4]. United Nations Conference on Trade and Development reported that global B2C e-commerce reached USD 3.9 trillion in 2017 [5] and Accenture and Ali Research in 2016 forecasted that cross-border e-commerce will reach USD 1 trillion in 2020 [6].

The role of digital platforms. Digital platforms, which are specially designed multi-sided marketplaces for electronic commerce, have played a major role in the expansion of online sales. The most important element in the process is the interaction between the participants provided by electronic means. In fact, digital platforms enable the buyers and the sellers (or any other side or participant group) to contact with each other and carryout different commercial transactions. Therefore, the two key characteristics of digital platforms are: 1) each group of participants (side) are customers or sellers of the multi-sided platforms in some 
meaningful way, and 2) the multi-sided platform enables a direct interaction between the sides [7].

By enabling direct interaction, digital platforms allow business, especially smaller businesses, to efficiently penetrate the global marketplace and gain access to the millions of consumers across the world. Truly, the research of the IPC found that almost two out of three or $57 \%$ of cross-border supplies of goods are made through the three biggest digital platforms. If we take into the account many other domestically and regionally operating platforms, it is estimated that roughly two thirds of all e-commerce supplies are purchased via digital platforms with only one third made through direct sales (see figure 1).

Figure 1. Global online (e-commerce) sales

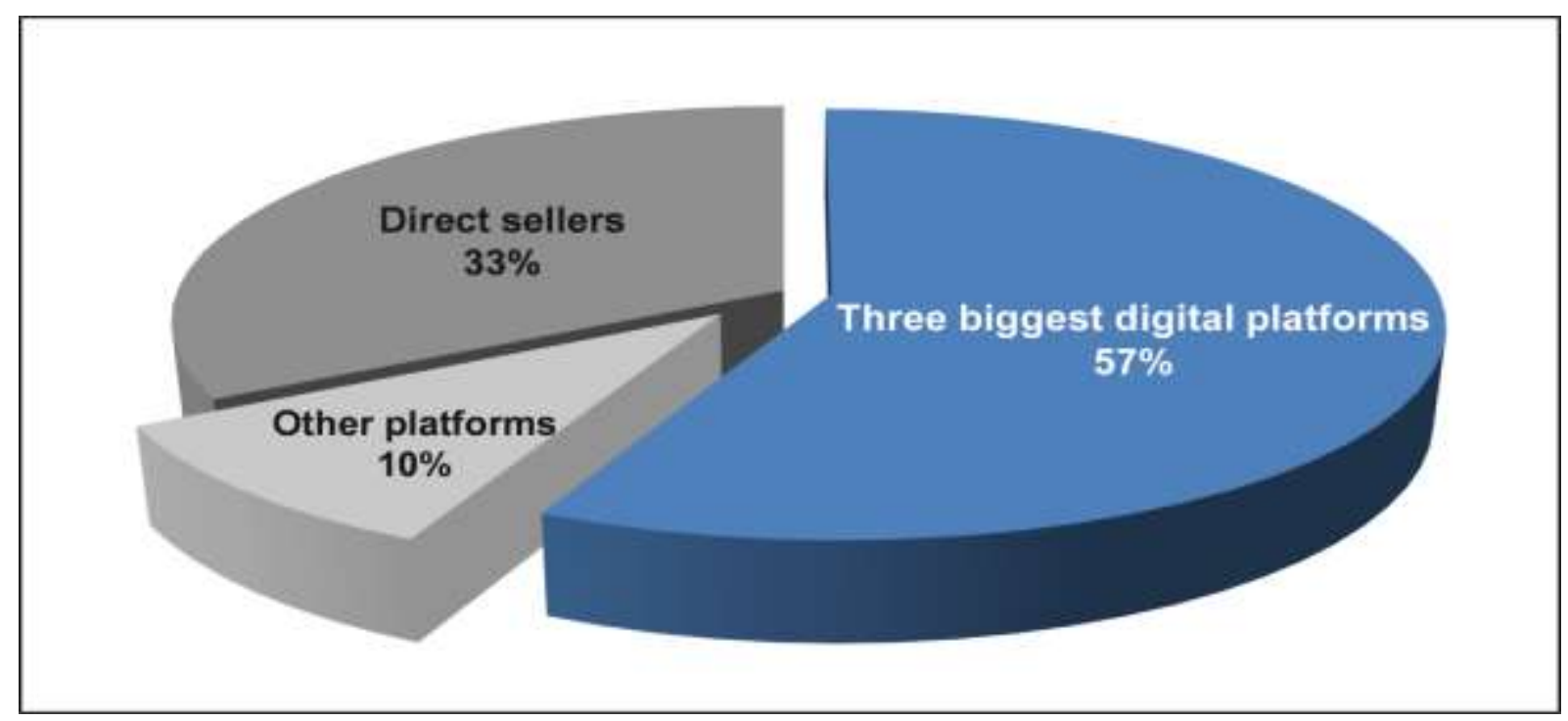

Source: IPC Online Shopper Survey 2017 reports.

\section{Chalenges of VAT/GST Collection on Online Sales}

Considering the growth of online sales generated by the expanding digitalization and and at the same time magnified by the pandemic restrictions, the ammounts of VAT/GST that are prospectivelly at stake are enourmous. The importance of this potential revenues are even more signifficant when the financially exhausted countries will face the enavitable phaze of their fiscal consolidation.

There are a couple of main chalenging issues considering the VAT/GST revenue colection that were recently identified by the OECD [9]: 1) The problem of collecting suffiecient revenues from the imports of low-value goods from online sales which are treated as VAT/GST exempt in many jurisdictions; 2) Chalenges at the tax and customs admimnistration in respect of the collection of VAT/GST at importation; and 3), the problem with the strong growth in the trade of services and intangibles, on which often no or a very low amount of VAT/GST is levied due to the complexity of enforcing VAT/GST payment on such supplies.

The controversy of VAT/GST exemption from the imports of low value goods (1). The main reason why many jurisdictions impose an exemption from VAT/GST on the imports of low-value goods is because the administrative costs associated with it outweigh the VAT/GST revenues that would be collected on those goods. Indeed, this approach from the authorities earned its justification in the period before the emergance of digital economy and internet shoping didn't exist as we know it today. Meanwhile, this has been changed over the years as the countries have experienced a rapid growth in the volume of imports of these low-value goods, resulting with potentially large revenue losess on their tax accounts. The exemption from VAT/GST on imports of the relevant goods have additionally put competitive presure on domestic retailers, creating for them un unfair position, as they are still required to charge taxes 
on their domestic sales. From this point of view, the exemption of VAT/GST on the imports of low value goods is controversial, influencing unfair competition for domestic retailers and generating direct tax revenue losess.

Chalenges at the tax and customs administration. We have to mention that these institutions have legal obligation to collect the relevant taxes at importation above the VAT/GST threshold and customs duties above the minimis exemption threshold. The experts agree that simply by removing the exemption (the thresholds) for the low value goods, and adding an additional obligation for the tax and customs administration in regards to collect the revenues is absolutely not an option. The reasons behined this are twofold: First, these institutions, especially the customs authorities carry out many other crutial tasks including the facilitation of trade, the control of illegal activities such as drugs and weapon trafficing, the control of piracy and the protection of intellectual property rights, or even more sophisticated functions such as the control of money laundring and fight against the threat of terrorism. Such a solution without supporting measures is likely to be counter-productive, with customs having to control more consignments with knock-on effects for other functions [10]; And second, tax and customs administrations are allready facing challenges in respect of the collection of VAT/GST at importation above the VAT/GST threshold. To support this claim, a 2016 study using real purchases, estimated a non-compliance rate of $65 \%$ for all e-commerce supplies from outside the EU to EU consumers via the postal channel (these inculde the goods below the VAT/GST threshold and de minimis threshold for customs dities) [11].

Chalenges with the cross-border trade of services and intangibles. Concidering this issue, the complex nature of the process to enforce and charge VAT/GST payment on such supplies is resulting with collection of insufficient ammouts of revenues by the tax and customs authorities. Here, the recommendations for the countries are to examine the possiblities that the digital platforms could play the role of a service or intermediary in the collection of VAT/GST revenues. The logic behind this approach is that the platform is viewed as taking the role of a "store" with an offering of different supplies such as digital supplies of music, films, books, games and software applications, and in many cases act as the sole point of contact with the end consumer including in respect of service delivery [12]. In this sence, the digital platforms are indeed, viewed as an efficient and effective mechanism capable of delivering a positive results for the purpose of collection of VAT/GST from the cross-border trade of services, intangibles and digital products. In the same way, the involvment of digital platform could also resolve the chalenging issues mentioned from above and replace the tax and customs administation in their task of collection of VAT/GST at the importation of low value goods.

\section{Definition of the Term "Digital Platform" in the Context of Application of the Full Liability Regime}

The term "digital platform" is a relatively new concept and it is constantly evolving as the digital economy continues to develop. Generally, the OECD uses this term „as a generic term to refer to the actors in online sales that carry out the functions that can be considered essential for their enlistment by tax authorities in the collection of VAT/GST on online sales" [13]. These can essentially be described as the platforms that enable groups such as buyers and sellers to interact directly and execute transactions, through the use of information technology and electronic means. Jurisdictions that have enlisted such groups or actors in the collection of VAT/GST on online sales, in practice use several other terms to adress these actors, including: „platforms”, „marketplaces”, or „intermediaries”.

The key criteria that a tax authority must consider when deciding if the digital platforms should be enlisted in the collection of VAT/GST under a full VAT/GST liability regime is their ability to conform with the obligations of a full VAT/GST liability regime. Accordingly, it is reasonable to assume that a platform will be in a position to comply with these obligations if two conditions are met: a) the platform holds or has access to sufficient and accurate information as required to make the appropriate VAT/GST determination; and b) the platform has the means to collect the VAT/GST on the supply [14]. 
Whether a digital platform is indeed in a position to comply with such a regime may often depend on its business and delivery model, in addition it could be required a particuliar analysis and consultation to be done with the individual platforms. In this case, the authorities could apply the approach to explore the functions performed by digital platforms and other critaria that can generally indicate that the digital platform is able to operate under a full VAT/GST liability regime. The following table 1 contains examples of the possible functions that could be considered by the authorities if they want to determine whether or not a digital platform is capable of complying with the full VAT/GST liability regime.

Table 1 List of possible functions (indicators) considered relevant for enlisting digital platforms under full VAT/GST liability regime

\begin{tabular}{|c|c|}
\hline $\begin{array}{c}\text { Functions that may trigger the eligibility of } \\
\text { digital platform for the full VAT/GST liability } \\
\text { regime }\end{array}$ & $\begin{array}{l}\text { Functions that may exclude digital platform } \\
\text { from eligibility for the full VAT/GST liability } \\
\text { regime }\end{array}$ \\
\hline $\begin{array}{l}\text { Controlling and/or setting the terms and } \\
\text { conditions of the underlying transactions } \\
\text { (price; payment terms; delivery conditions, etc.) } \\
\text { and imposing these on participants (buyers, } \\
\text { sellers transporters...); }\end{array}$ & $\begin{array}{l}\text { Only carries content (e.g. makes only the } \\
\text { Internet network available for carrying content via } \\
\text { Wi-Fi, cable, satellite, etc.); }\end{array}$ \\
\hline $\begin{array}{l}\text { Direct or indirect involvement in the payment } \\
\text { processing (either directly or indirectly through } \\
\text { arrangements with third parties, collect payments } \\
\text { from customers and transmit these payments to } \\
\text { sellers less commissions etc.); }\end{array}$ & Only processes payments; \\
\hline $\begin{array}{l}\text { Direct or indirect involvement in the delivery } \\
\text { process and/or in the fulfilment of the supply } \\
\text { (influencing/controlling the conditions of delivery; } \\
\text { sending approval to suppliers and or instructing a } \\
\text { third party to commence the delivery etc.) }\end{array}$ & Only advertises offers; \\
\hline $\begin{array}{l}\text { Providing customer support services (returns } \\
\text { and/or refunds/assistance with dispute } \\
\text { resolution). }\end{array}$ & $\begin{array}{l}\text { Only operates as a click-through/shopping } \\
\text { referral platform. }\end{array}$ \\
\hline
\end{tabular}

Source: OECD research.

Countries can decide how deep in detail can they go when they want to acquire indicators for the inclusion of digital platforms in the scope of such a regime. One possible solution would be to differentiate the functions that may trigger the eligibility of digital platform (positive list) from the functions that may exclude digital platform from eligibility for the regime (negative list). The use of detailed indicators for platforms inclusion in, or exclusion from a full VAT/GST liability regime, has the advantage of enhancing certainty for both - digital platforms and tax authorities. Further, the authorities are advised to follow the broader principals when setting the indicators for digital platforms eligibility for a full VAT/GST liability regime, as determined by the OECD study [15]:

- The indicators for the eligibility of digital platforms for a full VAT/GST liability regime should be based on functions rather than on types of platforms or business models;

- In the cases where more than one digital platform in a supply chain is eligible for a full VAT/GST liability regime, tax authorities could consider applying hierarchy rules;

- Any approach for defining the digital platforms' eligibility for a full VAT/GST liability regime will need to be reviewed regularly in light of technological and commercial developments to ensure their efficiency and effectiveness;

- Consulting with the business community is of vital priority for the design and the effective operation of a full VAT/GST liability regime;

- It is of trustworthy importance to provide clear and easily accessible information on the indicators for digital platforms that fall under the full VAT/GST liability regime etc. 


\subsection{When to consider implementation of the full VAT/GST regime for digital platforms}

Here we analyse some crucial considerations for tax authorities when scoping the full VAT/GST liability regime for digital platforms as offered by the OECD guidance. Sometimes the countries must make important decusions when or in which cases should they apply the rules of the full liability regime: wheather they should include the foreign suppliers and/or only domestic suppliers, should the rules differ for foreign digital platforms from the ones for domestic platforms, only to apply them in the case of goods (low value goods or all goods) or to add the trade of services and intangibles, to focus only on the B2C supplies or maybe to deal with the B2B supplies as well.

Low-value goods vs all goods. The following lines refer to the possibilities from the implementation of the full VAT/GST regime on the supplies of goods from online sales that are directly connected with an importation of these goods. As we mentioned, the problem focuses primarily on the online sales of imported low-value goods below the VAT/GST threshold and the de minimis threshold for customs duties subject to exemption. Data suggest that such imports of low-value goods represent the vast majority of packages that reach the borders from online trade, and create increasingly significant logistical challenges for customs authorities to process [16]. According to Bowes, the volume of these sales increased from 44 billion in 2014 to 65 billion in 2016 across 13 major markets and continues to increase at a growing rate that is calculated to be $17-28 \%$ each year between 2017 and 2021. This increase has been facilitated by technological innovation, which have dramatically increased digital platforms and underlying suppliers capacity to deliver goods to customers worldwide against increasingly lower costs and within increasingly shorter delivery times [17].

For this reason, in 2015 the OECD has proposed an alternative approach, whereby the VAT/GST on imports of low-value goods from online sales would be collected and remitted by digital platforms, which at the time of their proposal were differently known as transparent $e-$ commerce platforms [18]. Accordingly, „transparent e-commerce platforms are platforms that provide a trading framework for vendors but that are not parties to the commercial transaction between the vendor and the purchaser. These platforms generally have access to the key information that is needed for assessing the VAT/GST due in the country of importation of lowvalue goods". The model described from above, could provide an efficient and effective solution in therms of collection of VAT/GST on importation of low value goods, but only if the countries manage to deliver simple compliance regimes accompained with fast-track processing. If the model is fully implemented, it is expected to lower the cost of collection of VAT/GST on imports of low-value goods remarkably, allowing the customs authorities to focus their capacities to the other important duties they perform.

Services/intangibles vs all services. The dillema here is whether to apply the full liability regime only to the specific services such as the digital/electronic services or to all services being subject to importation. It seems that the majority of jurisdictions support the idea to limit the scope of the full VAT/GST liability regime only to the digital platforms that are involved in remote digital/electronic supplies by foreign suppliers. These typically include the following categories of supplies: digital content purchases (downloads of e-books, videos, apps, games, music); subscription-based supplies of content (news, music, streaming of video, online games); supplies of software services and maintenance (anti-virus software, digital data storage, software); licensing of content; telecommunication and broadcasting services. The reason behined this is to ensure proper collection of VAT/GST on supplies in those sectors that are considered as "risky" and generate insufficient tax revenue ammounts. The other argument for the reliability of digital platforms here is, the complexity of supply chain for the digital products, which is always long and complicated. Digital platforms are perfect solution as they are able to target the stage of the ultimate supply to the final customer, which is usually the critical moment when taxes are being charged or remmited.

Foreign digital platforms vs domestic digital platforms. Generally, jurisdictions shouldn't make any difference whether the operating digital platform is from a resident or by a nonresident origin. Nevertheless, it could be more chalenging for the authorities to reduce the risk of non-compliance in the case when a foreign digital platform is present in the country, in which 
case an additional safeguard measures must be introduced. Another critical point here is the possible interaction (collision) between the domestic and the international legislative rules imposed under the full VAT/GST liability regime.

Foreign suppliers vs domestic suppliers. In the previous paragraph we pointed that the primary reason for the implementation of a full VAT/GST liability regime was the need to strenghten the compliance and control of millions potentially underlying foreign suppliers and enforce the collection of taxes. Nonetheless, the exclusive restriction of the full VAT/GST regime to transactions that originate from underlying suppliers located in foreign countries could increase auditing chalenges for tax authorities, for example, to verify the location of the principal supplier, control tax payments and remmitance etc. These examinations back the usability of the full VAT/GST liability regime to the transactions from all the relevant suppliers regardless the location they come.

$B 2 B$ vs $B 2 C$ supplies. Payment transactions in trade, usually differ between B2B (businessto-business) transactions and B2C (business-to-consumer) transactions. The first B2B is a transaction that tends to happen in the supply chain, conducted between one business and another, such as a wholesaler and retailer. B2C is a transaction between the business and the consumer, normally happening in final stage of the supply chain. According to the recomendations of OECD, in the countries that do not distinguish between $\mathrm{B} 2 \mathrm{~B}$ and $\mathrm{B} 2 \mathrm{C}$ supplies, the full VAT/GST liability regime could be applied for the collection of VAT/GST on both categories of supplies performed via a digital platform [19]. Where a jurisdiction makes difference between B2B and B2C supplies, the general rule would be that the full VAT/GST liability regime intended to be implemented on B2C supplies, must not affect, interfere or replace the existing collection mechanisms for inbound B2B supplies. These are known as the reverse-charge mechanisms when the business customer has a full right to deduct the input tax (absence of the obligation to remit the tax) or the mechanism for tax paymemnt deferal to a later stage usually applied in the case of importation of goods [20]. Where different rules are in power for B2B and B2C supplies, determination of the status of customer (business or consumer) is essential for enforcement of the correct VAT/GST treatment of an ongoing supply, as the guidance of OECD suggest in their Collection Mechanisms Report [21]. The same report rules out that when the digital platform is unable to establish the status of its customer, it must presume that the customer comes from the non-business sector, so that the rules for $\mathrm{B} 2 \mathrm{C}$ supplies would be administered.

\section{Description of the Full VAT/GST Liability Regime}

Under the full VAT/GST liability regime, the digital platform is designated by law as the subject liable to collect and supply the relevant VAT/GST revenues on behalf of the state (legal supplier for VAT/GST liability purposes). Under this regime, the digital platform is exclusively and fully liable for assessing, collecting and remitting the VAT/GST on the online sales that go through the platform, to the tax authorities in the jurisdiction of taxation [22]. In direction with the VAT/GST legislation, this liability regime must be limited to VAT/GST obligations only, avoiding the other liability aspects for digital platforms. The picture from below provides a symplified description of the basic operation of a full VAT/GST liability regime.

Picture 1 Basic operation of a full VAT/GST liability regime 


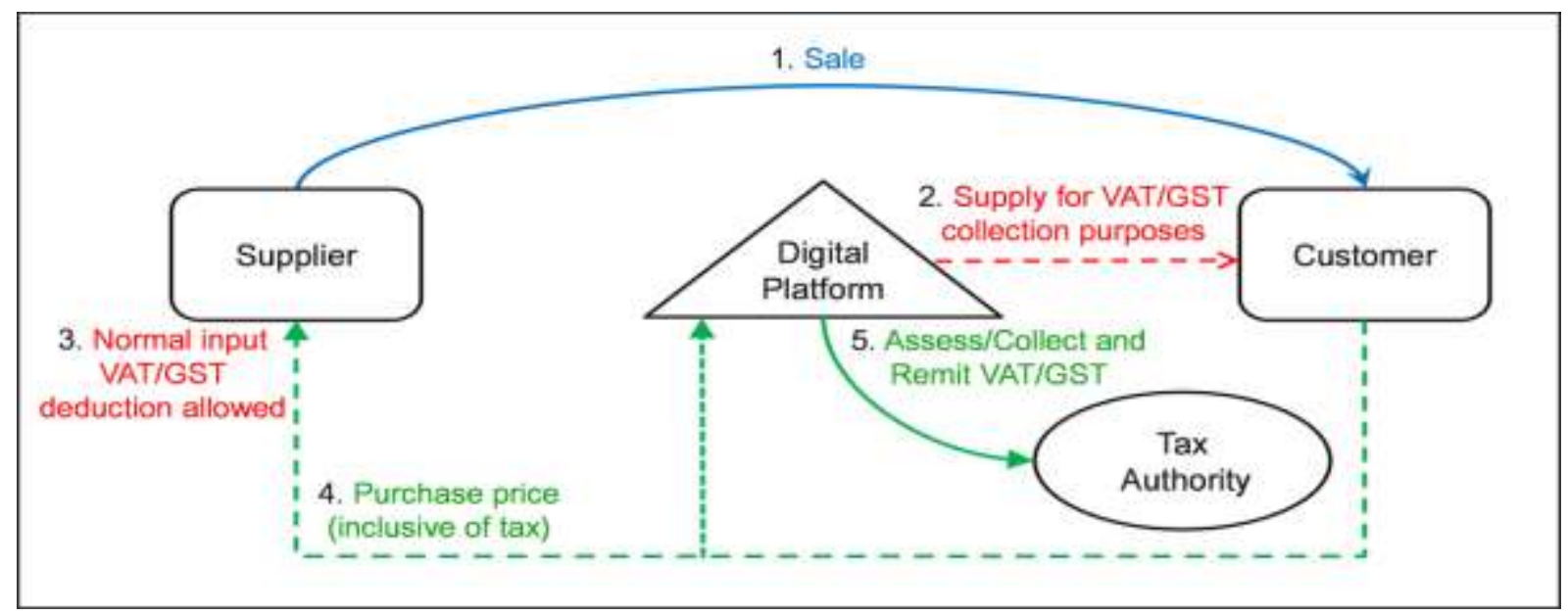

Source: OECD research.

The numbers in the picture are indicators of a numerous operations and paths through wich the full VAT/GST liability regime is carried out:

Sale. An underlying supplier makes an online sale through a digital platform to a customer in the jurisdiction of taxation.

Supply for VAT/GST collection purposes. As it is mentioned, the digital platform through which the sale was carried out is fully and exclusively liable for the VAT/GST from the particuliar sale, as determined by the laws in the jurisdiction of taxation. The mechanism for the collection and payment of the VAT/GST is described by the following steps [23]:

- The digital platform takes full VAT/GST liability assuming as if it has realized the underlying sale to the customer itself;

- The principal supplier is relieved from any VAT/GST liability on the sale to the customer, for the purpose of avoiding double taxation;

- In order to escape a break in the supply chain, this regime treats the digital platform as a part of it (assuming as if the digital platform has received the supply from the supplier and has carried it onwards to the final customer in the jurisdiction of taxation);

- All of these steps in the supply chain are backed by a proper documentation covering for auditing purposes in accordance with the full VAT/GST liability regime in the jurisdiction of taxation (it is advisible that the documentation and the reporting requirements are simple and conveniant).

Normal input VAT/GST deduction allowed. In essence, the full VAT/GST liability regime should enable the underlying supplier to retain the right to deduct the input VAT/GST accordingly.

Purchase price (inclusive of tax). The ultimate customer can pay for its purchase either to the digital platform (in which case the digital platform will remit the tax to the authority in the jurisdiction of taxation) or to the underlying supplier (in which scenario the involved platform must recover the tax component from the principal supplier and transfer it to the tax authorities from the country of taxation).

Assess/collect and remit VAT/GST. This operation is a reminder connection indicating on the central role of the digital platform as being fully and solely liable for assessing, collecting and remitting the VAT/GST from the primary sale and for any other related compliance obligations.

\subsection{Determination of the taxing point as a crucial element of the full VAT/GST liability regime}


In the context of a proprer fulfilment of the underlined obligations to assess, collect and remit the VAT/GST given to digital platforms, determination of the taxing point represents one critical moment for the right function of the full liability regime. Accordint to the OECD, the taxing point under the full VAT/GST liability regime is defined as ,the time at which the digital platform is required to account for the VAT/GST on the supplies carried out through its platforms for which it has liability" [24]. Since the digital platforms are only assumed as being the actual supplier, they may not always have all the necessary information to resolve the taxing point as written by the standard VAT/GST rules, such as time of receipt of payment, time of actual supply, time of delivery etc. Consequently, this will create an additional complexity and compliance burden for the digital platforms for further investigation having in mind the countless supplies carried out on a daily basis.

So, a practical solution has been made to determine the taxing point ,at the time at which the confirmation of the payment is received by or on behalf of the underlying supplier". Actually, this is the time at which the payment has been accepted or authorised by or on behalf of the underlying supplier. Of course, the actual transfer may still have not been made [25]. If we resume, the taxing point under the full VAT/GST regime is the time of confirmation of the payment (acceptance or authorisation of the payment by the the principal supplier).

For a better understanding of the underlying issue of the taxing point, the OECD provides a simple illustration of the basic payment processing cycle as shown in the following picture.

Picture 2 The simplified payment cycle

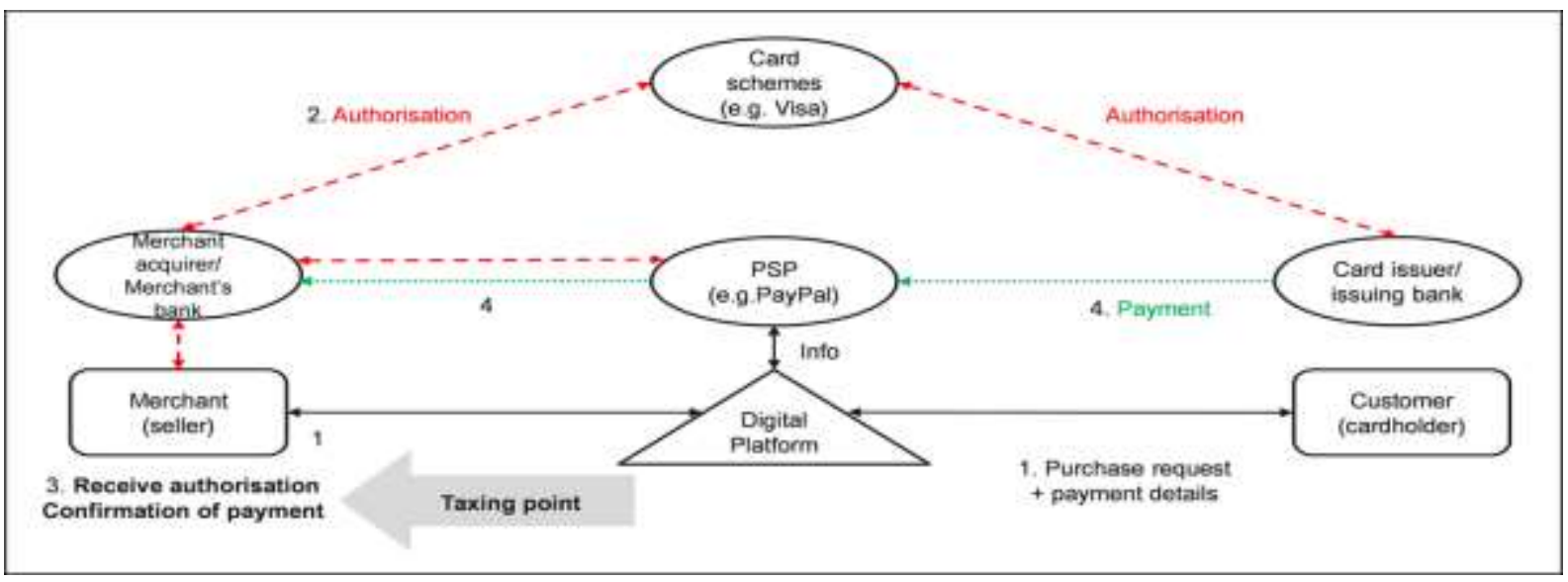

Source: OECD analysis.

A typical online payment process usually involves 5 subjects (parties) each playing a key role during the cycle:

> Customer (the cardholder) - a person holding a debit or credit card issued by card issuer (the issuing bank, in this case, the customer's bank);

$>$ Seller (the underlying supplier) - it is a merchant (vendor) that sells goods and/or services to the customer;

$>$ Seller's bank (the acquiring bank) - it is a bank or a financial institution that processes the payment transaction on behalf of the seller/merchant.

$>$ Card scheme - it is a central payment network that uses credit and debit cards to process payments (for example, American Express, Maestro, MasterCard, Visa, etc.);

$>$ Customer's bank (the issuing bank) - it is the bank or financial institution that provides debit or credit card to the cardholder.

$>$ Payment service provider - the payment service provider offers online services for accepting electronic payments by a variety of payment methods including credit and debit card, bank transfers, real-time bank transfer based on online banking (for example, PayPal securely takes customer's card details on a payment page and passes these onto the acquiring bank for processing). 
The typical online payment process can be explained through the next 4 steps of the payment cycle [26]:

* The customer (the cardholder) decides to purchase an item from the seller. Therefore, he/she initiates communication offer for purchase to the seller, either through a digital platform or directly. At this stage, the customer provides the seller with card details for the future payment.

* After receiving the customer's offer to purchase, the seller initiates an authorisation request that will be passed onto the customer's bank (the card issuer). Subsequently, the customer's bank confirms the authorisation and sends it back to the seller.

* The third step is crucial as it defines the moment of taxation. Once the seller receives authorisation [which is the taxing point under the full VAT/GST liability regime], the seller accepts the purchasing offer and delivers the item to the customer. Meanwhile, the customer's bank places a hold (lock) on the amount of the purchase on the customer's account. Afterwards, the seller informs the digital platform about the confirmation of payment while the digital platform notifies the customer.

* The final stage is about the collection request made by the seller. Upon his initiation, the customer's bank transfers the funds to the seller's bank account. Finally, the customer's bank will collect (recover) the transaction amount from the customer's account.

The small discussion of the payment process explicitly reveils the point of taxation, defined as the moment when the digital platform receives notification from the underlying supplier about the confirmation of payment, from which point the digital platform becomes fully and exsclusively liable for assesing, collecting and remiting VAT/GST associated with the particuliar order.

\subsection{Taxing point at the importation of low-value goods}

There is quite difference between the standard model of taxation and the proposed model of full VAT/GST liability when the matter is importation of low value-goods. For that reason, first we present the traditional collection model, where the tax and customs duties are usually assessed at the time of importation - at the border. The whole procedure is illustarted on the following picture.

Picture 3 The traditional collection model during the importation of low-value goods

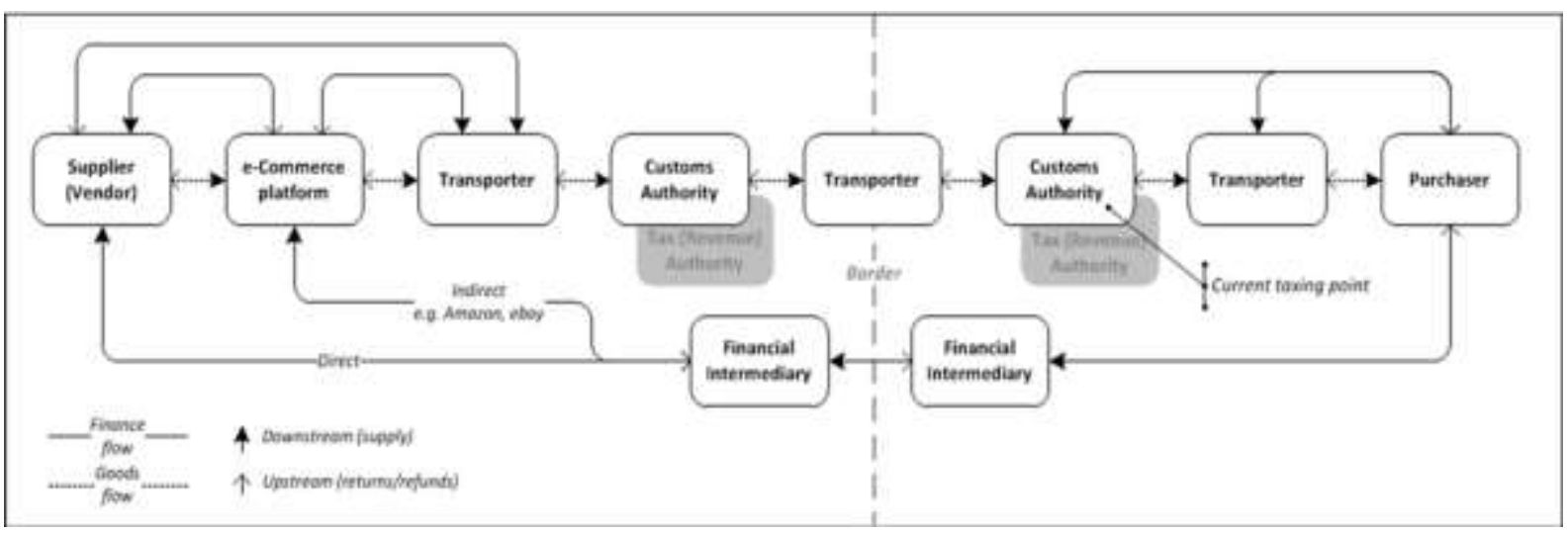

Source: OECD. „Addressing the Tax Challenges of the Digital Economy, Action $1-2015$ Final Report", Paris, 2015;

The picture obviously reveals the current taxing point (at the border), which is in accordance with the standard procedures of the traditional collection model. Although each country may have different customs and taxing procedures, these generally follow similar patterns: when a low-value good is imported, the person liable to pay the duties and taxes is the recipient of the goods (with other words, the declarant mentioned on the customs declaration). During the 
importation at the border, the VAT/GST and the customs duties from the importation of lowvalue goods are assessed and collected by the customs authorities in line with customs procedures. For imports of goods from online sales, the customs clearance procedure is typically carried out by the express couriers or postal operators that are involved in transporting the goods, as declarants [27]. Other actors involved in the customs clearance as well as revenue collection procedures may include: the customs brokers i.e. persons engaged by the vendor, the carrier or the importer that are in charge for managing the data required for the clearance and entry of imports and to pay duties and taxes that are due, the freight forwarders who are mainly rendering services of any kind relating to the carriage, consolidation, storage, handling, packing or distribution of the goods and others.

In the model of full VAT/GST liability regime, the definition of the taxing point by reference to the time of confirmation of the payment, in the area of importation of low-value goods translates at the time prior to shipping or arrival of goods at the border [28]. This solution practically moves the collection of the VAT/GST on the goods from online sales away from the border, reduces the need for customs authorities to intervene in the VAT/GST collection, and leaves them more space to focus on more important task such as the safeguarding of health and security. This rule is particularly attractive and useful for imports of good that have a value below the de minimis customs threshold.

For comparison purposes, we present in the next picture the model of full VAT/GST liability regime on imports below the customs threshold. The taxing point is efectively "moved away" from the border line, at the time before shipment and arrival of the goods at the border line, thus liberating space and time for the customs authorities for more sophisticated activities. Once again digital platforms have the central role in the process which in coordination of the customs and tax authorities assess, collect and remit the VAT/GST on the imported supplies. Another crucial obligation of digital platforms is to provide information for those institutions and/or to coordinate and provide the flow of information between the supplier and overseas transporters.

However, for a successful accomplishment of this outcome, the full VAT/GST liability regime that imposes obligation on digital platforms to assess, collect and remit the VAT/GST on supplies of imported low-value goods from online sales needs to include a measure that removes the obligation to pay import VAT/GST at the border on the relevant goods [29].

Picture 4 The model of full VAT/GST liability regime on imports below the customs threshold.

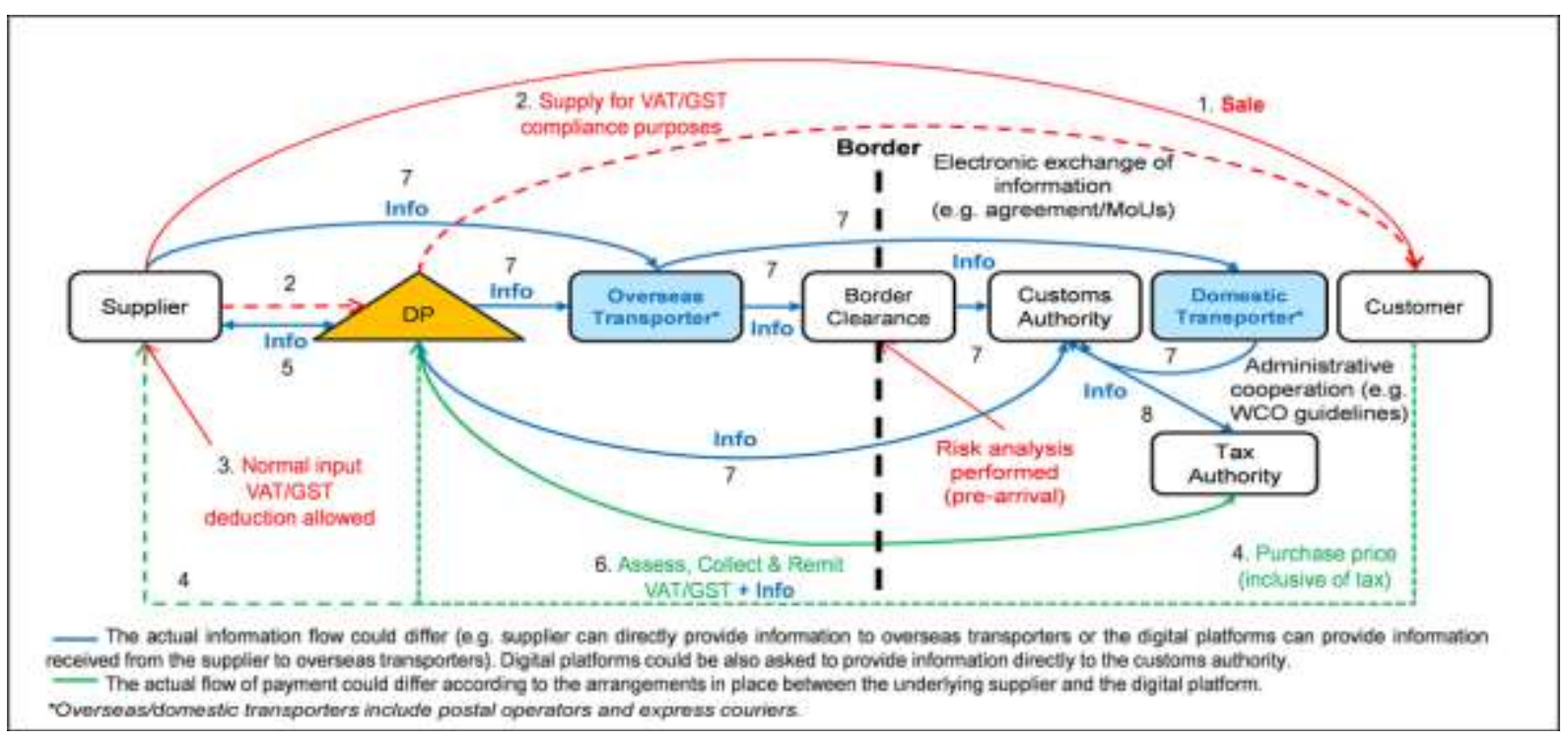

Source: OECD analysis.

\subsection{Basic information needs}


There are some basic information needs for digital platforms in order to achieve full and correct tax determination under the full VAT/GST liability regime. Firts and most important, the operating digital platform must assume that the underlying suppliers using the platform to expand their sales are in fact businesses unless they have information indicating to the oposite. The costs and efforts to obtain such an information must be reasonable. Other information requirements that are concidered relevant for digital platforms to make the correct VAT/GST determinations under the full liability regime may include [31]:

$\checkmark$ Customer status (this is important when B2B differs to B2C in terms of the tax jurisdiction);

$\checkmark$ The nature of the supply;

$\checkmark$ Elements to determine the place of taxation;

$\checkmark$ Elements to determine the applicable VAT/GST collection regime;

$\checkmark$ What is the VAT/GST exemption threshold;

$\checkmark$ The value of the supply;

$\checkmark$ The applicable VAT/GST rate; and

$\checkmark$ What (or where) is the taxing point at which VAT/GST liability occurs.

All these information elements may be fammiliar to digital platforms or could be additionlly obtained. This system of the basic information needs is known as the "business systems approach" which helps the digital platforms to provide the most fundamental indormation to perform accurate calculation of its VAT/GST liability.

\section{The simplified registration and compliance system}

The highest levels of effectiveness in the collection of VAT/GST on online sales by digital platforms are likely to be achieved if compliance obligations in the jurisdiction of taxation are limited to what is closely necessary and the rules of registartion for non-resident suppliers are rigorously simplifiied. These are described by the OECD in the Collection Mechanisms Report providing guidance for the effective operation of this mechanism in practice [30]. When a digital platform is liable under the full VAT/GST regime for both goods and services into a particular jurisdiction, the simplified registration and compliance system could be applied for the both supplies, which in turn would decrease the administrative and compliance costs. As recommended by the OECD, the features of a simplified registration and compliance regime system for non-resident suppliers, if the country intends to implement the full VAT/GST liability regime for digital platforms, should reffer to several issues:

Registration procedure. Simplification of the procedure for registration reqiures inclusion of limited information only to the most important details such as: name of business, name of contact person, his/her telephone number and e-mail address, postal and registered address of the business, website URL of non-resident suppliers through which business is conducted in the taxing jurisdiction, national tax identification number, etc. The easiest and most practical way to engage with tax administrations from a distant location is by electronic processes, so an on-line registration application could be useful to enter the tax administration's website.

Payments. The best way for payment is by electonic means (methods), that allows the nonresident suppliers to remit the tax electronically, preferably in the currency of the tax jurisdiction, although payments in domicile currencies of the trading partners should be accepted.

Invoicing. Generally, countries are advised to eliminate the invoicing reqirements for B2C supplies that fall under the the simplified registration and compliance regime. This is due to the simple fact that final consumers, which are the ultimate taxpayers in the supply chain, lose their right to deduct the input VAT paid on these supplies. If invoices are required after all, the same rule for limited information should be applied (includig the identification of the customer, type and date of the supply, the taxable amount - tax base, the VAT rate in persent and the total amount of VAT payable). Jurisdictions should tolerate invoices written in the languages of the trading partners.

Input tax recovery refunds. For simplification purposes, jurisdictions should not alow the recovery refunds of input tax under the simplified registration and compliance regime to the 
collection of VAT on B2C supplies. Of course, input tax recovery refunds could stay in force under the normal VAT registration and compliance procedure for the non-resident suppliers.

Tax return filing procedure. Once again, jurisdictions should aim to simplify the procedure as much as possible, balancing between the need for simplicity and the need to control and verify if tax obligations have been correctly assessed and filed. Thus the basic information within the file of tax return could be be restricted to: registration identification number of the supplier, tax period, type of currency, taxable amount at the standard rate, taxable amount at the reduced rate, total tax amount payable. Preferably, the format of the file should be electronic.

Record keeping. Recomendations for the countries are to enable extensive use of electronic record keeping systems. Minimal record requirements should include: the type of supply, the date of the supply, the VAT payable and the information used to determine the place where the customer has its usual residence. The records kept by the non-resident supplier must be available on request to the relevant taxing jurisdistion.

\section{Implementation of the Full VAT/GST Liability Regime}

The model of full VAT/GST liability regime, in which digital platforms play the central role in the process of collection of taxes, is not a mandatory obligation for the jurisdictions across the globe, having in mind the principles of tax autonomy and fiscal sovereignty. It is rather a voluntary proposition, a trend among the most advanced and leading countries in the field of economic reforms, which gives opportunity for the rest of the world to improve and at the same time lessen the whole process of compliance of VAT/GST from online sales. In principal, taxing jurisdictions make their own decision wheather to implement or not the proposed measure taking into account differences and priorities in policy and legislative environments, administrative capacities, experience and culture, as well as their challenges in the field of taxation.

Nevertheless, if the countries do intend ti implement this tax policy approach, they are encouraged to ensure as much consistency as possible in an international context. To reach the desired compliance levels in terms of quality and performance, and at the same time notably reduce the compliance costs, the OECD reassures that the countries follow the presented policy design considerations when implementing a liability regime for digital platforms [32]:

* Consultation with the business community. This is important to determie the level of acceptance of the proposed measure. It is also relevant to reach out to the involved digital platforms as well as other subjects in the supply chain that are likely to be affected by the regime.

* Publicise the introduction of the regime. This step accelerates and promotes the intoduction of the reform, provides wide and adequate recognition of it's benefits and creates sufficient time for the national agencies as well as digital platforms to adjust themselves to the ongoing reform.

* Promote simplified compliance system. Compliance obligations of VAT/GST must be restricted to the level that is strictly necessary to facilitate the compliance process and to ensure the correct and effective collection of the VAT/GST on online sales. This is especially of signifficant importance to the non-resident digital platforms.

* Avoid collision with the normal VAT/GST regime. Jurisdictions must ensure that the liability regime is not in conflict with the standard VAT/GST deduction rules at the level of the underlying supplier (in terms of legal formality).

* Provide equilization between registration and sales thresholds. If a system of thresholds exists in the jurisdiction of taxation, it is vital to determine if there is a difference between the threshold set at the level of the platform and the ones set at the level of each underlying supplier (multy-level threshold system). Here, the suggestions are to apply a threshold at the level of the platform, which is likely to reduce the compliance burden especially for for SMEs and micro-enterprises, but will also increase the compliance costs for the suppliers that are currently below the threshold level. 
* Make sure not to violate the neutrality principle in international trade. Neutrality in VAT/GST in international trade is achieved by the the implementation of the destination principle, which is an important valuable property of this tax. Under the destination principle, no VAT/GST is levied on exports, and imports are taxed at the same rate and according to the same rules in the jurisdiction of destination as if they had been domestic production [33]. Thus, there is no tax related distorsion in the composition of the country's exports and no advantage in buying from a low or zero tax jurisdiction. The implementation of the full VAT/GST regime also requires from the tax authorities to incorporate this relevant principle respectfully, within the new tax policy frame.

* Improve the co-operation and coordination between the tax and customs authorities. This is of great importance, since the obligation to collect and remmit VAT/GST at the importation of low-value goods is transferred from the customs authorities to digital platforms, so a better sinchronization of these activities is more than an obvious requirement. The need for this co-operation is also recognised by the WCO Framework of Standards [34].

* Strenghten and intensify administrative co-operation between tax authorities to enforce compliance. Predominantly, this includes the exchange of information to identify the parties in supply chain of the import process, monitoring the value of sales during imports and assessing if the correct amounts of VAT/GST have been collected and remitted to the authorities (from the taxing jurisdiction) [35]. The countries are encouraged to adopt the use of technological means to detect non-compliant digital platforms, in order to reduce the supply chain risk and promote legitimate trade.

At the end, we present the possible implementation timeframe for the full VAT/GST liability regime, which is, as we can see consisted of minimum 12 months.

Picture 5 Timeframe for implementation of the full VAT/GST liability regime.

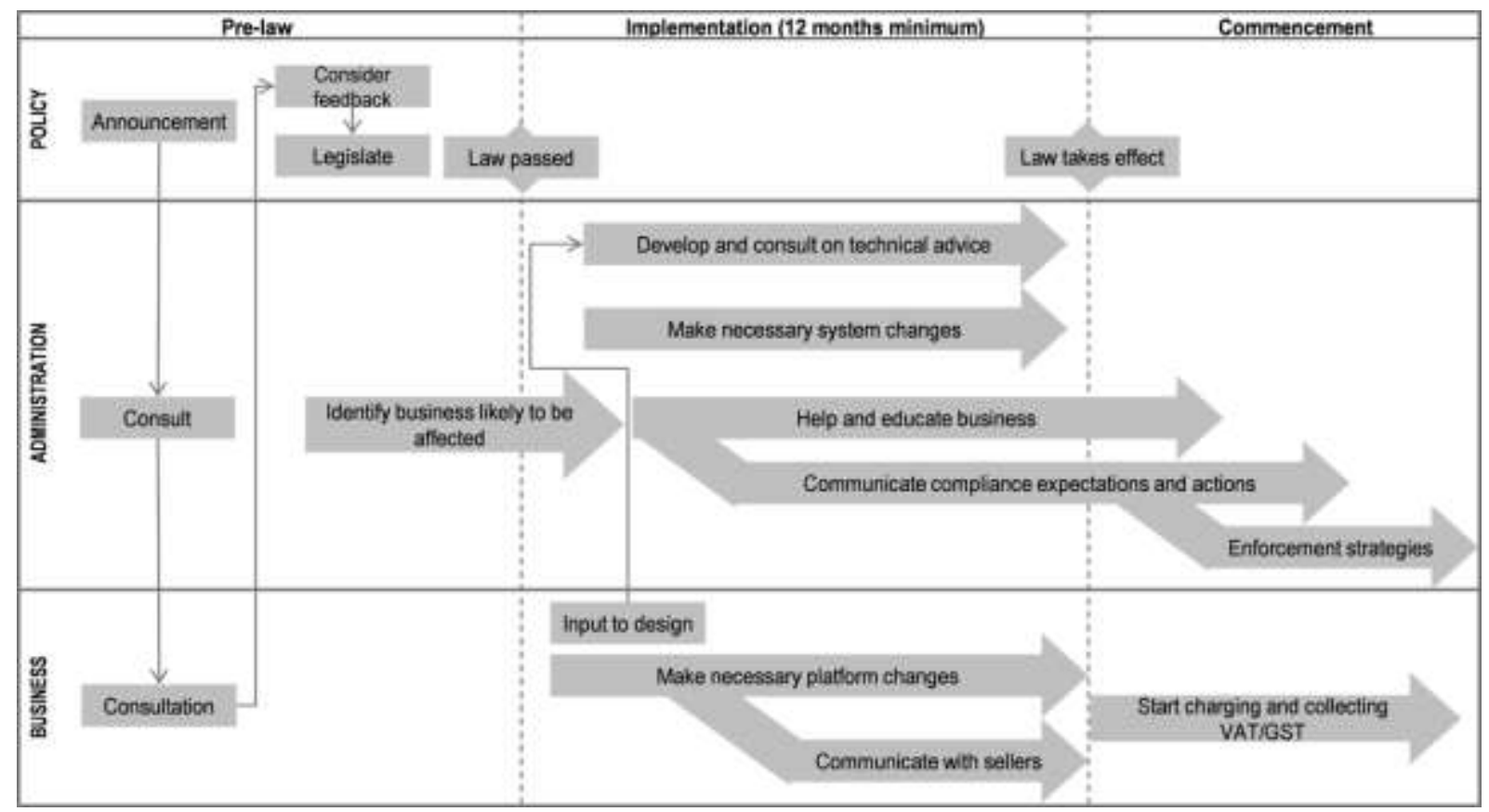

Source: OECD analysis.

\section{Conclusion}

This article presents short elaboration of the OECD practical guidelines and principles on the design and implementation of the possible solutions for involvement of digital platforms as a viable VAT/GST collection means. The intention is to offer an alternative solution, an initial 
general frame for the possible implementation of such a similar measure, hopefully taking part of the post-covid consolidation plans that every country must consider. To better understand the reason behind the full VAT/GST liability regime, first we capture the dimension of the explosive growth of online sales as a result of the process of digitalization in the economy, where digital platforms and the other electronic marketplaces play the central role. After addressing to the challenges of VAT/GST collection on online sales, definition of the term "digital platform" is explained. During the detailed description of the full VAT/GST liability regime, the importance of determination of the taxing point is annotated, especially at the importation of low-value goods. Shortly after, the requirements for the basic information needs of digital platforms are given, all for the purpose of full and correct tax determination under the full VAT/GST liability regime. All this is in the context with the simplified registration and compliance system, considering the fact that the highest level of effectiveness in the collection of VAT/GST is likely to be accomplished if compliance obligations in the jurisdiction of taxation are limited to only that is closely vital. At the end, the proposed policy frame for the implementation of the full VAT/GST liability regime is elaborated, with the possible timeframe for implementation of roughly 12 months.

\section{References}

1 OECD. „The VAT/GST collection challenges of digital trade and the role of digital platforms in addressing them", An OECD study, Paris, 2019;

2 eMarketer. „Retail Ecommerce Sales Worldwide, 2016-2021“, 2018;

3 Asia-Pacific Economic Cooperation. „Electronic Commerce Steering Group“, 2018;

4 World Trade Organization. „WORLD TRADE STATISTICAL REVIEW 2018“, 2019;

5 United Nations Conference on Trade and Development. „Global e-Commerce sales surged to \$29 trillion“, 2019;

6 Accenture and AliResearch. „Global Cross Border B2C e-Commerce Market 2020“, 2016;

7 OECD. „The VAT/GST collection challenges of digital trade and the role of digital platforms in addressing them“, An OECD study, Paris, 2019;

8 International Post Corporation. „IPC Online Shopper Survey 2017 reports“, 2017.

9 OECD. „Addressing the Tax Challenges of the Digital Economy, Action 1 - 2015 Final Report, OECD/G20 Base Erosion and Profit Shifting Project", OECD, Paris, 2015;

10 OECD. ,The VAT/GST collection challenges of digital trade and the role of digital platforms in addressing them", An OECD study, Paris, 2019;

11 Basalisco, B., J. Wahl and H. Okholm. „E-Commerce Imports into Europe: VAT and Customs Treatment", 2016.

12 OECD. „International VAT/GST Guidelines“, OECD Publishing, Paris, 2017;

13 OECD. "The digital platform as the person liable for the VAT/GST on online sales (platform VAT/GST liability regimes)", Paris, 2019;

14 OECD. „The digital platform as the person liable for the VAT/GST on online sales (platform VAT/GST liability regimes)", Paris, 2019;

15 OECD. „The digital platform as the person liable for the VAT/GST on online sales (platform VAT/GST liability regimes)", Paris, 2019;

16 OECD. „Addressing the Tax Challenges of the Digital Economy, Action 1-2015 Final Report“, Paris, 2015;

17 Pitney Bowes. „Pitney Bowes Newsroom | Pitney Bowes Parcel Shipping Index Reveals 48 Percent Growth in Parcel Volume since 2014", 2017;

18 OECD. „Addressing the Tax Challenges of the Digital Economy, Action 1-2015 Final Report“, Paris, 2015;

19 OECD. "Other aspects of designing the scope of a full VAT/GST liability regime", Paris, 2019;

20 OECD. „Mechanisms for the Effective Collection of VAT/GST - OECD“, Paris, 2017;

21 OECD. „International VAT/GST Guidelines, OECD Publishing, Paris“, Paris, 2017;

22 OECD. "Full VAT/GST liability regime“, Paris, 2019;

23 OECD. "Mechanisms for the Effective Collection of VAT/GST - OECD“, Paris, 2017;

24 OECD. „Full VAT/GST liability regime“, Paris, 2019;

25 OECD. „VAT/GST collection and payment process under the full VAT/GST liability regime“, Paris, 2019; 
26 OECD. „Addressing the Tax Challenges of the Digital Economy, Action 1 - 2015 Final Report“, Paris, 2015;

27 OECD. „Addressing the Tax Challenges of the Digital Economy, Action $1-2015$ Final Report", Paris, 2015;

28 Section III of the WCO Cross-Border E-Commerce Framework of Standards on Fair and Efficient Revenue Collection;

29 OECD. „Full VAT/GST liability regime“, Paris, 2019;

30 OECD. „Mechanisms for the Effective Collection of VAT/GST - OECD“, Paris, 2017

31 OECD. "The digital platform as the person liable for the VAT/GST on online sales (platform VAT/GST liability regimes)“, Paris, 2019;

32 OECD. „International VAT/GST Guidelines“, OECD Publishing, Paris, 2017;

33 OECD. „Full VAT/GST liability regime“, Paris, 2019;

34 Section III of the WCO Cross-Border E-Commerce Framework of Standards on Fair and Efficient Revenue Collection;

35 OECD. „Supporting measures for efficient and effective collection of VAT/GST on online sales", Paris, 2019; 